\title{
A STUDY ON OCCUPATIONAL STRESS AMONG THE DOCTORS WHILE ENGAGING THE COVID-19 TREATMENTS
}

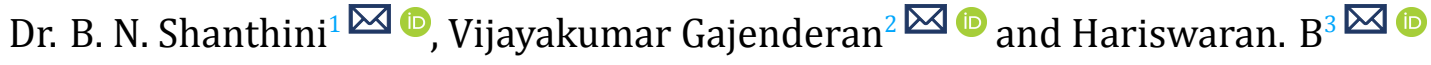 \\ ${ }^{1}$ Assistant Professor, Department of Commerce, Govt Arts and Science College. Dr.Radhakrishnan Nagar.Chennai 81, India \\ ${ }^{2}$ Assistant Professor \& Research Supervisor, Department of Commerce, Sir Theagaraya College, Chennai-600 021, India \\ ${ }^{3}$ Assistant Professor, Department of Commerce, Mar Gregorios College of Arts and Science, Chennai, India
}
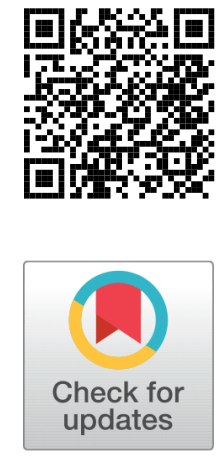

Received 1 May 2021

Accepted 19 May 2021

Published 31 May 2021

Corresponding Author

Dr. B. N. Shanthini, shanthini_bn@

yahoo.co.in

DOI $10.29121 /$

granthaalayah.v9.i5.2021.3917

Funding: This research received no specific grant from any funding agency in the public, commercial, or not-for-profit sectors.

Copyright: (C) 2021 The Author(s). This is an open access article distributed under the terms of the Creative Commons Attribution License, which permits unrestricted use, distribution, and reproduction in any medium, provided the original author and source are credited.

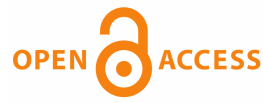

\section{ABSTRACT}

The present paper's focuses to measure the occupational stress among professional doctors while engaging the COVID-19 treatments in the study area. The pandemic of Coronavirus in India is element of the pandemic globally caused by the ruthless sensitive respiratory syndrome virus. The COVID-19 outburst has created fear, distress, anxiety, and depression amongst the doctors and the universal public. Doctors are predominantly prone to increase various mental health disorders than the general population.. The study exercised both primary and secondary data. The secondary data was collected related to Covid19 diseases, treatments of doctors. The primary data obtained from the doctors are engaging the COVID 19 treatments. The sample size of the study is 353 . The collected responses were converted into excel sheets and converted into SPSS software version 21 for analysis. The study used simple frequency distribution and t-test for testing the framed hypothesis. The study found that the doctors engaging covid-19 treatment, first six months, and 58\% of the doctors have high-level stress level. The study also found that the government hospital doctors significantly affected work culture while engaging the COVID-19 treatments in hospitals. The study confirmed that the government hospital doctors could not manage their work-life balance. The doctor has significantly affected their personal life and leads to occupational stress while engaging the COVID19 treatments in the study area.

Keywords: Occupational Stress, COVID19, Doctors

\section{INTRODUCTION}

The pandemic of Coronavirus in India is element of the pandemic globally caused by the ruthless sensitive respiratory syndrome virus. The first case was reported in India on 30 January 2020. India currently has the most significant number of positive cases in Asia and the second biggest number of postive cases after the United 
States Liu et al. (2020); Nadkarni et al. (2021). The COVID-19 outburst has created fear, distress, anxiety, and depression amongst the doctors and the universal public. Doctors are predominantly prone to increase various mental health disorders than the general population Gupta et al. (2020) . The GOI is taking all essential steps to make certain that to prepare the confront and threat posed by the mounting pandemic of COVID-19, the Corona Virus. The essential reason in preventing Virus from spread locally empower the populace with the accurate information and take precautions as per the advisories by the Ministry of Health \& Family Welfare. The Doctors who respond to the global health emergency working to defend people, families, and societies in conflicting positions with increased resources, deficiency of personal protective equipment, and other facilities discovered themselves as surprising victims in the aggressiveness against COVID-19 Gupta et al. (2020) Healthcare professionals, i.e., doctors, are directed to extra stresses in addition to the emotional repercussions of the cultural crisis due to ongoing difficulty in the execution of infected patients and increased risk of disease, the anxiety of communication to their families, concern for themselves, and the wellbeing of admired ones feeling stigmatized and private and administering under ultimate pressure. On the other hand, the figure of cases and illness-related deaths, excessive workload for an extended period, and worker safety equipment loss was exacerbated by mental and physical burnout over time (PPE) Pabalkar and Prakash (2020). The doctors are playing very significant role for fighting against the spreading the corona virus. Therefoere the present study is focused on measuring the occupational stress among the doctors while engaging the COVID-19 Treatments in the study area.

\section{REVIEW OF LITERATURE}

Nadkarni et al. (2021) stated that the COVID-19 pandemic had formed a turbulent stream in every human. While healthcare professionals encounter a different set of hindrances and difficulties that need special attention, many have also encountered a silver covering amidst this chaos in family life and lifestyle modifications. Notwithstanding, COVID-19 has been a game-changer for everyone. Pabalkar and Prakash (2020) orginated that the factors determined to be associated with higher workplace stress in line staff healthcare professionals were as stipulated: Augmented average operating hours, increased number of patients treated for Covid-19, decreased level of companion and supervisor assistance, lower logistic aid, and more pessimistic sentiments of performance through activities associated to Covid-19. Ngoc et al. (2018) observed a meaningful association between the ubiquity of occupational stress and strenuous workload and skill level. Consequently, hospitals need to accompany screening for all doctors, nurses, and medical personnel to recognize occupational stress and relevant intervention subjects. Dwivedi (2020) shows that 75.714 doctors fall under the average perceived stress score, which confronts a considerable measure of stress at their workplaces. In addition, the researchers recommend 
interventions at the hospitals to helping them cope with their stress. Gupta et al. (2020) revealed a great pervasiveness of anxiety and depressive symptoms between armed compulsions doctors. The primary contributing constituents are female gender, modern age group, non-clinical specialties, and has a doctoral degree. Zare et al. (2020) The predominance of COVID-19 has a meaningful impact on job stress in the HCWs of Iranian hospitals. Factors are high workload, despicable respond time at the crest of hospital visits, need of adequate sustain for top managers of every job cluster equally. In addition, the lack of introduction to sufficient personal protective equipment, the unpreparedness of managers and staff to counter to the critical and emergencies on stress frequency were influential on the present study. Giorgi et al. (2020) Administrative and employment features have a significant influence on psychological health, particularly in the circumstances of a global pandemic. The workplace, consequently, represents an indispensable target towards which applications should be directed to maintain mental health issues correlated COVID-19 pandemic. Mental problems compared with a health crisis, namely anxiety, depression, suicidal ideas, disorders, and alcohol addiction, are probable to affect healthcare peoples, particularly those on the front-line, migrant workers, and operators in connection with the public, comparable to the law enforcement.The review of literatue helps to develop the above mentioned research. In addition, based on the literarure survey the following objectives and hypotheses were framed.

\section{OBJECTIVES OF THE STUDY}

1. To study the work culture of government hospital doctors while engaging the COVID-19 treatments in hospitals

2. To assess the work-life balance among the government doctors while engaging the COVID -19 Treatments in the study area

3. To find out the personal factors among the government doctors while engaging the COVID -19 Treatments in the study area

\section{STATEMENT OF HYPOTHESIS}

1. Work Culture does not affect the government hospital doctors while engaging the COVID-19 treatments in hospitals

2. The work-life balance significantly affected the occupation stress among the government doctors while engaging the COVID -19 Treatments in the study area

3. The personal factors significantly affected the occupation stress among the government doctors while engaging the COVID -19 Treatments in the study area 


\section{RESEARCH METHODOLOGY}

The present paper's ultimate objective is to measure the occupational stress among professional doctors while engaging the COVID-19 treatments in the study area. The study exercised both primary and secondary data. The secondary data was collected related to Covid-19 diseases, treatments of doctors. The primary data obtained from the doctors are engaging the COVID 19 treatments. The participants of the study are doctors who were engaging in the COVID 19 treatments in government hospitals. The purpose of the study was to explain to doctors and convinced their confidentiality of their opinions. The doctors are requested to fill the responses through Google forms. The responses are obtained from the doctors from January 2021 to April 2021. The research contained questions related to demographic profiles and causes of occupational stress of doctors. The study used a convenience sampling method. Overall, 400 Google forms were distributed among the doctors. Out of 400, 353 Google forms were only filled and return. The sample size of the study is 353 . The collected responses were converted into excel sheets and converted into SPSS software version 21 for analysis. The study used simple frequency distribution and t-test for testing the framed hypothesis.

\section{RESULTS AND DISCUSSIONS}

\begin{tabular}{lll}
\hline $\begin{array}{l}\text { Table } 1 \\
\text { (n=353) }\end{array}$ & Demographic Profile of & Doctors \\
\hline $\begin{array}{l}\text { Demographic Profile } \\
\text { Gender }\end{array}$ & Frequency & Percent \\
\hline Male & 185 & 52.4 \\
\hline Female & 168 & 47.6 \\
\hline Age (Years) & & \\
\hline Up to 35 & 81 & 22.9 \\
\hline $36-45$ & 106 & 30.0 \\
\hline $46-55$ & 118 & 33.4 \\
\hline Above 55 & 48 & 13.6 \\
\hline Marital Status & & \\
\hline Single & 89 & 25.2 \\
\hline Married & 264 & 74.8 \\
\hline Professional Experience & \\
\hline Up to 5 & 53 & 15.0 \\
\hline $5.1-10$ & 132 & 37.4 \\
\hline 10.1 -15 & 105 & 29.7 \\
\hline$>15$ & 63 & 17.8 \\
\hline
\end{tabular}

Table 1 exhibits the results ofthe demographic Profile of government hospital doctors in the study area. Out of 353 sample doctors, $52.4 \%$ of the doctors are male, and $47.6 \%$ of the doctors are female category. Regarding the age classification of sample 
doctors, the majority, $33.4 \%$ of the sample doctors, are between $46-55$ years. It followed 30\% sample doctors between $36-45$ years, $22.9 \%$ of the doctors are up to 30 years, and $13.6 \%$ of the doctors are above 55 years. In addition, the majority, $74.8 \%$, of the doctors are married, and $25.2 \%$ of the doctors are single category.

Table 2 Stress severity among the Doctors during Treatment of COVID-19

\begin{tabular}{|lllll}
\hline Duration of Stress & $\begin{array}{l}\text { Stress Level during the COVID } \\
\text { Treatment }\end{array}$ & Total \\
& Low level & Medium level & High level & \\
\hline 1st six months & 20 & 35 & 76 & 131 \\
\hline & $15.3 \%$ & $26.7 \%$ & $58.0 \%$ & $100.0 \%$ \\
\hline 6-12 months & $29.4 \%$ & $26.5 \%$ & $49.7 \%$ & $37.1 \%$ \\
\hline & 14 & 55 & 52 & 121 \\
\hline 12 -18 months & $11.6 \%$ & $45.5 \%$ & $43.0 \%$ & $100.0 \%$ \\
\hline & 22 & $41.7 \%$ & $34.0 \%$ & $34.3 \%$ \\
\hline Above 18 months & $37.3 \%$ & $44.1 \%$ & 11 & 59 \\
\hline & $32.4 \%$ & $19.7 \%$ & $7.2 \%$ & $16.7 \%$ \\
\hline Total & 12 & 16 & 14 & 42 \\
\hline & $28.6 \%$ & $38.1 \%$ & $33.3 \%$ & $100.0 \%$ \\
\hline & $17.6 \%$ & $12.1 \%$ & $9.2 \%$ & $11.9 \%$ \\
\hline & 68 & 132 & 153 & 353 \\
\hline & $19.3 \%$ & $37.4 \%$ & $43.3 \%$ & $100.0 \%$ \\
\hline
\end{tabular}

Table 2 exhibits stress severity among the government hospital Doctors while engaging the COVID-19 treatment in the study area. The study results indicate that the doctors have high-level stress first six months (58\%). It is followed by $26.7 \%$ of the doctors have medium-level stress, and $15.3 \%$ of the doctors feel that low-level stress. In the treatment of COVID 19 between 6-12 months, the majority, 45.5\%, of the doctors have medium level stress, followed by $43 \%$ of the doctors who have highlevel stress, and $11.6 \%$ of the doctors have low-level stress while engaging the treatment of COVID 19. The covid19 treatment between $12-18$ months majority $44.1 \%$ of the doctors have medium-level stress, followed by $37.3 \%$ of the doctors having lowlevel stress, and $18.6 \%$ of the doctors have high-level stress the period. The COVID 19 treatment between above 18 months to till date majority $38.1 \%$ of the doctors have medium level stress, followed by $33.3 \%$ of the doctors have high-level stress, and $28.6 \%$ of the doctors have low-level stress. Overall, most $43.3 \%$ of the doctors have high-level stress while engaging the COVID 19 treatment, followed by $37.4 \%$ of the doctors having medium level stress, and $19.3 \%$ of the doctors have low-level stress.

\section{Null Hypothesis 1}

Work Culture does not affect the government hospital doctors while engaging the COVID-19 treatments in hospitals 
Table 3 Results of one-sample t-test for work culture of government hospital doctors while engaging the COVID -19 Treatments $n=353$

\begin{tabular}{lcccc}
\hline Work Culture & Mean & SD & t & p \\
Long working hours & 3.44 & 1.282 & 6.433 & $<0.001^{* *}$ \\
$\begin{array}{l}\text { Heavy work load } \\
\begin{array}{l}\text { The work is repetitive and } \\
\text { monotonous }\end{array}\end{array}$ & 3.56 & 1.315 & 7.971 & $<0.001^{* *}$ \\
$\begin{array}{l}\text { Sufficient time is not provided } \\
\text { to complete the work }\end{array}$ & 3.62 & 1.274 & 8.818 & $<0.001^{* *}$ \\
$\begin{array}{l}\text { No relaxation time provided } \\
\text { during the working hours }\end{array}$ & 3.65 & 1.174 & 9.929 & $<0.001^{* *}$ \\
\hline
\end{tabular}

Table 3 shows the results of a one-sample t-test for the work culture of government hospital doctors while engaging the COVID -19 Treatments in the study area. Since the p-valueof government hospital doctors' entire work culture while engaging the COVID, -19 Treatments are $<0.01$. The suggested null hypothesis was rejected and concluded that the government hospital doctors significantly affected the government hospital doctors while engaging the COVID-19 treatments in hospitals. It indicates that the entire statements of work culture significantly affected the government hospital doctors while engaging the COVID-19 treatments.

\section{Hypothesis-2}

The work-life balance significantly affected the occupation stress among the government doctors while engaging the COVID -19 Treatments in the study area

Table 4 Results of one-sample t-test for work-life balance affected the occupational stress among the doctors $(n=353)$

\begin{tabular}{lcccc}
\hline \multicolumn{1}{l}{ Work-Life Balance } & Mean & SD & t & p \\
\hline $\begin{array}{l}\text { I'm too drained after work I never go out } \\
\text { with my loved ones }\end{array}$ & 2.43 & 1.323 & -.985 & .325 \\
$\begin{array}{l}\text { I typically miss my kid's games and dif- } \\
\text { ferent exercises }\end{array}$ & 2.46 & 1.259 & -.655 & .513 \\
$\begin{array}{l}\text { I'm relied upon to work extended peri- } \\
\text { ods to accomplish my objectives }\end{array}$ & 2.40 & 1.183 & -1.642 & .101 \\
$\begin{array}{l}\text { Rigid work hours cause ailment like } \\
\text { carelessness in childcare, homegrown } \\
\text { issues, family issues and so forth }\end{array}$ & 2.47 & 1.257 & -.487 & .627 \\
\hline
\end{tabular}

Table 4 reveals the results of a one-sample t-test for managing the work-life balance among the government hospital doctors in the study area. The outcome indicates that the $p$-value of entire statements of work-life balance is $>0.05$. Therefore the study confirmed that the proposed null hypothesis is accepted and concluded that government hospital doctors could not manage their work-life balance. The study inferred that the government doctors significantly affected that their working hours extended and they cannot fulfill their objectives (2.40), it is followed by the doctors 
are not able to spend time with their families during the period of COVID-19(2.43), the doctors typically miss my kid's games and different exercises (2.46), and 'Rigid work hours cause ailment like carelessness in childcare, homegrown issues, family issues and so forth' (2.47)

\section{Null Hypothesis-3}

The work-life balance significantly affected the occupation stress among the government doctors while engaging the COVID -19 Treatments in the study area

Table 5 Results of one-sample t-test for personal factors affecting the occupational stress among the government doctors $(n=353)$

\begin{tabular}{lllll}
\hline Personal factors & Mean & SD & t & p \\
\hline Lack of Gloves/ Masks/ PPE Kits & 2.64 & 1.330 & 2.020 & $.044^{*}$ \\
\hline Nature of the job and its responsibilities & 2.55 & 1.381 & .636 & .525 \\
$\begin{array}{l}\text { Infection Prone Physical work environ- } \\
\text { ment (Isolation Wards/Quarantine Cen- }\end{array}$ & 2.50 & 1.279 & .021 & .983 \\
ters/Clinics/Hospitals/Nursing Homes) & & & & \\
\hline $\begin{array}{l}\text { Compromise of Personal Safety } \\
\text { Disregard of Personal health issue }\end{array}$ & 2.41 & 1.224 & -1.413 & .158 \\
\hline
\end{tabular}

Table 5 exhibits the results ofa one-sample t-test for personal factors affecting occupational stress among government doctors. The study results mentioned that the personal factors, namely 'Lack of Gloves/ PPE Kits,' Masks (t-value=2.020 \& $\mathrm{p}=0.044$ ), and 'Disregard of Personal health issue' ( $\mathrm{t}$-value $=-2.330 \& .020$ ), these two statements $p$-values are $<0.05$, therefore study indicates that the proposed hypothesis rejected and confirmed that the doctors are satisfied with the two statements. The rest of the personal factors p-values are $>0.05$; the proposed null hypothesis accepted and concluded that the doctor significantly affected their personal life and led to occupational stress while engaging the COVID-19 treatments in the study area.

\section{DISCUSSIONS}

The present paper focuses on measuring the occupational stress among professional doctors while employing the COVID-19 treatments in the study area. The study concluded that one of the prime purposes for occupational stress among experienced doctors is socio-ecological factors. The Socio-ecological causes, namely having an infant or a sick, older adult in the house, frequently take care of the pandemic while accomplishing responsibilities as doctors. Jones-Bonofiglio (2020). The other important causes of occupational stress among professional doctors are Infection-contracting physicians leads to gross understaffing at healthcare facilities. The doctors are dealing with long working hours and constantly shifting assignments, and working in an unfamiliar atmosphere, those results in immense emotional distress, even for the new teammates. It is exacerbated by unparalleled quarantine/isolation conditions and rigid interpersonal distance management. Western 
research shows that after the pandemic, doctors are also bound by the provincial order not to operate in several locations, resulting in financial difficulties Nadkarni et al. (2021).

Doctors operating in the high-risk sector are at increased risk of exposure to infections(Lu et al., 2020). The study's outcome estimates that as many as 87.5 percent of doctors have been contaminated with COVID-19. Such a high chance of exposure to illness leads doctors to feel anxiety, pain, and stress. It is often compounded by the possibility that their loved ones may be contagious, leading to significant mental health concerns Liu et al. (2020). In the ongoing COVID-19 to overcome the viral disease, the prevention of physical touch is considered to be an essential step. Due to this, doctors are forced to keep their closed ones apart, depriving them of the emotional connectivity they otherwise crave.

Furthermore, retaining social distance from their family members leads to a lack of emotional participation from the relevant members who lead to interpersonal conflict and mental health concerns. Working with a limited stock of personal safety devices for front-line doctors is not uncommon. Such a condition leads to panic and distress among doctors. However, excessive use of PPEs has also been reported to be a significant cause of distress among physicians. Research reveals that PPE is a considerable obstacle to communicating effectively with the patient and colleagues; functioning mostly with PPEs throughout extended durations, in turn, also leads to extreme burnout. Quarantine is an essential step in the pandemic to mitigate contamination. Front-line doctors also have to operate in segregated wards where they are the patients' primary care providers.

Doctors suffer from burnout and often feel the absence of self-control in the absence of much-needed internal contact and social reinforcement. In addition, front-line doctors frequently have to live in isolation, depriving them of emotional assistance from close medical friends and family members, resulting in numerous psychological disorders. Isolation/quarantine is an essential step in the pandemic to mitigate contamination. Front-line doctors also have to operate in segregated wards where they are the patients' primary care providers. Doctors suffer from burnout and often feel the absence of self-control in the absence of much-needed internal contact and social reinforcement. The study's outcome indicates that the doctors engaging in the COVID-19 treatment significantly affected occupational stress. It leads to some adverse behavior of doctors. Occupational stressors contribute to organizational incompetence, soaring employees turnover, absenteeism owing to sickness, diminished excellence and measure of practice, increased healthcare charges, and reducing the job satisfaction. One of the organizational outcomes that concerned by occupational pressure is job performance. 


\section{CONCLUSIONS}

The present paper focuses on measuring the occupational stress among professional doctors while engaging the COVID-19 treatments in the study area. The COVID-19 pandemic has created a tumultuous wave in every human's personal and professional lives on the planet. While doctors face a exceptional set of obstacles and dilemmas that want special attention, several have also experienced a silver lining amidst this chaos in the form of family life and lifestyle changes. Regardless, COVID-19 has been a game-changer for everyone. It is observed from the study; the doctors engaging covid-19 treatment, first six months, 58\% of the doctors have high-level stress level. The second six months, i.e., 6-12 months, the majority of $45.5 \%$ of the doctors, have medium-level stress. The third six months, i.e., $12-18$ months, majority $44.1 \%$ of the doctors have medium-level stress, and the above 18 months, $38.1 \%$ of the doctors have medium level stress. The study also found that the government hospital doctors significantly affected the government hospital doctors while engaging the COVID-19 treatments in hospitals. It indicates that the entire statements of work culture significantly affected the government hospital doctors while engaging the COVID-19 treatments. The study confirmed that the government hospital doctors could not manage their work-life balance. The doctor has significantly affected their personal life and leads to occupational stress while engaging the COVID-19 treatments in the study area.

\section{REFERENCES}

Dwivedi, S. P. M. (2020). Stress among doctors during COVID-19. The International Journal of IndianPsychology, 8(2).

Giorgi, G., Lecca, L. I., Alessio, F., Finstad, G. L., Bondanini, G., Lulli, L. G., Arcangeli, G., \& Mucci, N. (2020). COVID-19-Related Mental Health Effects in the Workplace: A Narrative Review. International Journal of Environmental Research and Public Health, 17(21), 7857-7857. Retrieved from https://dx.doi.org/10.3390/ijerph17217857 10.3390/ ijerph17217857

Gupta, S., Kohli, K., Padmakumari, P., Dixit, P. K., Prasad, A. S., Chakravarthy, B. S., Shukla, R., Ghana, P., Mahapatra, D., \& Varadaraj, G. (2020). Psychological Health Among Armed Forces Doctors During COVID-19 Pandemic in India. Indian Journal of Psychological Medicine, 42(4), 374-378. Retrieved from https://dx.doi.org/10.1177/ 0253717620934037 10.1177/0253717620934037

Iyengar, K. P., Jain, V. K., \& Vaishya, R. (2020). Current situation with doctors and healthcare workers during COVID-19 pandemic in India. Postgraduate Medical Journal.

Jones-Bonofiglio, K. (2020). A Socio-Ecological Perspective. Health Care Ethics through the Lens of Moral Distress, 39-52.

Liu, Z., Han, B., Jiang, R., Huang, Y., Ma, C., Wen, J., \& Ma, Y. (2020). Mental Health Status of Doctors and Nurses During COVID-19 Epidemic in China. SSRN. Retrieved from https:// papers.ssrn.com/sol3/papers.cfm?abstract_id=3551329 http://dx.doi.org/10.2139/ ssrn.3551329

Lu, J., Gu, J., Li, K., Xu, C., Su, W., Lai, Z., \& Yang, Z. (2020). COVID-19 outbreak associated with air conditioning in restaurant. Emerging Infectious Diseases, 26(7), 1628-1628. 
Nadkarni, T., Patel, S., Pawar, A., \& Bodhanwalla, M. (2021). Impact of COVID-19 Pandemic on the Life of Indian Doctors: Time for Introspection? (Vol. 11). EManuscript Technologies. Retrieved from https://dx.doi.org/10.5530/ijmedph.2021.2.15 10.5530/ ijmedph.2021.2.15

Ngoc, A. N., Thanh, X. L. T., Thi, H. L., Tuan, A. V., \& Van, T. N. (2018). Occupational Stress Among Health Worker in a National Dermatology Hospital in Vietnam. Frontiers in Psychiatry, 10.

Pabalkar, V., \& Prakash, S. (2020). Occupational Stress among Indian Doctors during COVID19. European Journal of Molecular \& Clinical ..., 7(11), 20-36.

Zare, S., Esmaeili, R., Naseri, S., \& Panahi, D. (2020). Occupational Stress Assessment of Health Care Workers ( HCWs ) Facing COVID - 19 Patients in Iran. Research Square, 1-14. 